\title{
Higher incidence of aseptic loosening caused by a lower canal filling ratio with a modified modular stem in total hip arthroplasty
}

Kyosuke Kobayashi* ${ }^{*}$, Kenichi Kidera, Masaru Itose, Tetsuhiko Motokawa, Ko Chiba and Makoto Osaki

\begin{abstract}
Purpose: Although a cementless modular prosthesis has shown reliable results, cases of unstable fixation and revision due to aseptic loosening were observed in our institute. The purpose of this study was to clarify the causes of unstable fixation of the prosthesis.

Methods: A total of 144 patients (154 hips) who underwent total hip arthroplasty using the modular prosthesis were retrospectively investigated. For the cohort study, 97 patients (104 hips) were included. The femoral component survival rate and sleeve fixation were assessed at a minimum follow-up of 5 years. Patients were divided into 2 groups, including stable and unstable fixation groups, by sleeve fixation. Clinical and radiographic outcomes were compared.

Results: The Kaplan-Meier survival rate at 9 years was $93 \%$ with revision for any reason as the endpoint in study cohort. The reasons for revision were recurrent dislocation (1 hip) and aseptic loosening of the stem (5 hips). A total of 88 hips (84.6\%) showed stable fixation, and 16 hips (15.4\%) showed unstable fixation at final follow-up. There was no significant difference in clinical outcomes between the 2 groups at final follow-up. The canal flare index was significantly higher, and the canal filling ratio was significantly lower in the unstable fixation group.

Conclusion: Although the modified modular prosthesis was useful for treating anatomically difficult patients, we need to pay attention to both proximal/distal mismatch of the intramedullary canal and the canal filling ratio to achieve stable fixation and good long-term results.
\end{abstract}

Keywords: THA, Modular prosthesis, Aseptic loosening, Canal filling ratio

\section{Introduction}

Even though monoblock total hip arthroplasty (THA) has shown excellent and reliable long-term results $[1,2]$, it has been difficult to treat complicated cases, such as developmental dysplasia of the hip (DDH), postosteotomy of the hip, and higher posterior pelvic tilt. In Japan, more than $80 \%$ of hip joint osteoarthritis

\footnotetext{
* Correspondence: kyo-kobayashi@nagasaki-u.ac.jp Nagasaki University Hospital, 1-7-1 Sakamoto, Nagasaki, Nagasaki 852-8501, Japan
}

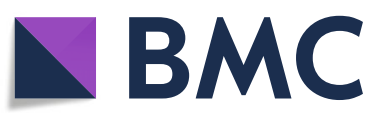

C C The Author(s). 2020 Open Access This article is licensed under a Creative Commons Attribution 4.0 International License, which permits use, sharing, adaptation, distribution and reproduction in any medium or format, as long as you give appropriate credit to the original author(s) and the source, provide a link to the Creative Commons licence, and indicate if changes were made. The images or other third party material in this article are included in the article's Creative Commons licence, unless indicated otherwise in a credit line to the material. If material is not included in the article's Creative Commons licence and your intended use is not permitted by statutory regulation or exceeds the permitted use, you will need to obtain permission directly from the copyright holder. To view a copy of this licence, visit http://creativecommons.org/licenses/by/4.0/ The Creative Commons Public Domain Dedication waiver (http://creativecommons.org/publicdomain/zero/1.0/) applies to the data made available in this article, unless otherwise stated in a credit line to the data.

patients had DDH [3, 4]. Selection of the femoral component is one of the most important points to gain primary and secondary fixation and prevent dislocation arising from lesser or greater femoral anteversion, a narrower medullary canal [5], bone deformity of the acetabulum and femur, and higher pelvic tilt. A modular prosthesis was one of the options to treat such cases, even though there were possible complications, such as fretting, corrosion, dissociation, and failure at the junction of the modular system [6-8]. 
In 1984, the S-ROM system (DePuy, Warsaw, IN) was developed as a modular prosthesis to treat these various types of anatomical deformities. This prosthesis is composed of a sleeve and stem body so that surgeons can change stem anteversion as they like to prevent dislocation. In addition, surgeons can treat various intramedullary canal shapes to select the stem and sleeve separately from various sizes. In 2004, the S-ROM-A prosthesis was developed as a modification of the $\mathrm{S}$ ROM stem for Asian patients who have a smaller body and narrower medullary canal. The S-ROM-A prosthesis has a shorter stem length with a bullet tip to reduce thigh pain and periprosthetic fracture and a 9/10 neck taper to reduce implant impingement.

There are some reports of the short- to long-term results of the S-ROM [9-12] and S-ROM-A [13-16] prosthesis for primary THA. Although excellent fixation rates (99.5-100\%) have been reported, with no evidence of aseptic loosening, we had cases of unstable fixation and revision due to aseptic loosening. The purpose of this study was to clarify the causes for unstable fixation of the stem. The hypothesis was that the canal filling ratio of the sleeve and stem is associated with unstable fixation.

\section{Material and methods}

All procedures performed in this study involving human participants were in accordance with the ethical standards of the institutional and/or national research committee and with the 1964 Helsinki Declaration and its later amendments or comparable ethical standards.

The Institutional Review Board approved the study and waived informed consent.

The medical records of 144 patients (154 hips) who underwent primary THA using the S-ROM-A prosthesis between July 2009 and January 2014 were retrospectively reviewed. Patients who were followed up less than 5 years (34 hips), those who underwent subtrochanteric shortening osteotomy (5 hips), and those with a metal on metal bearing surface (10 hips) were excluded. The pre-operative clinical outcome of one patient was not available. Therefore, 97 patients (male, $n=20$; female, $n$ = 77; mean age at surgery, 62 (36-84) years; follow-up, 8 (5-10) years; hips, $n=104$ ) were assessed (Fig. 1). The underlying diagnoses were osteoarthritis $(n=7$; primary, $n=89$; secondary), rheumatoid arthritis $(n=1)$, trauma $(n=2)$, rapidly destructive coxarthropathy $(n=3)$, and osteonecrosis $(n=2)$.

The criteria for using the stems were severe deformity including DDH (Crowe 2 or 3) and post-osteotomy, femoral anteversion $<10^{\circ}$ or more than $40^{\circ}$, pelvic tilt angle $>25^{\circ}$ [17], or patients at high risk for dislocation, such as those with mental disorders or Parkinson's disease. Of all the patients, 87 (83.4\%) were diagnosed with osteoarthritis secondary to DDH, 21 patients $(20.2 \%)$

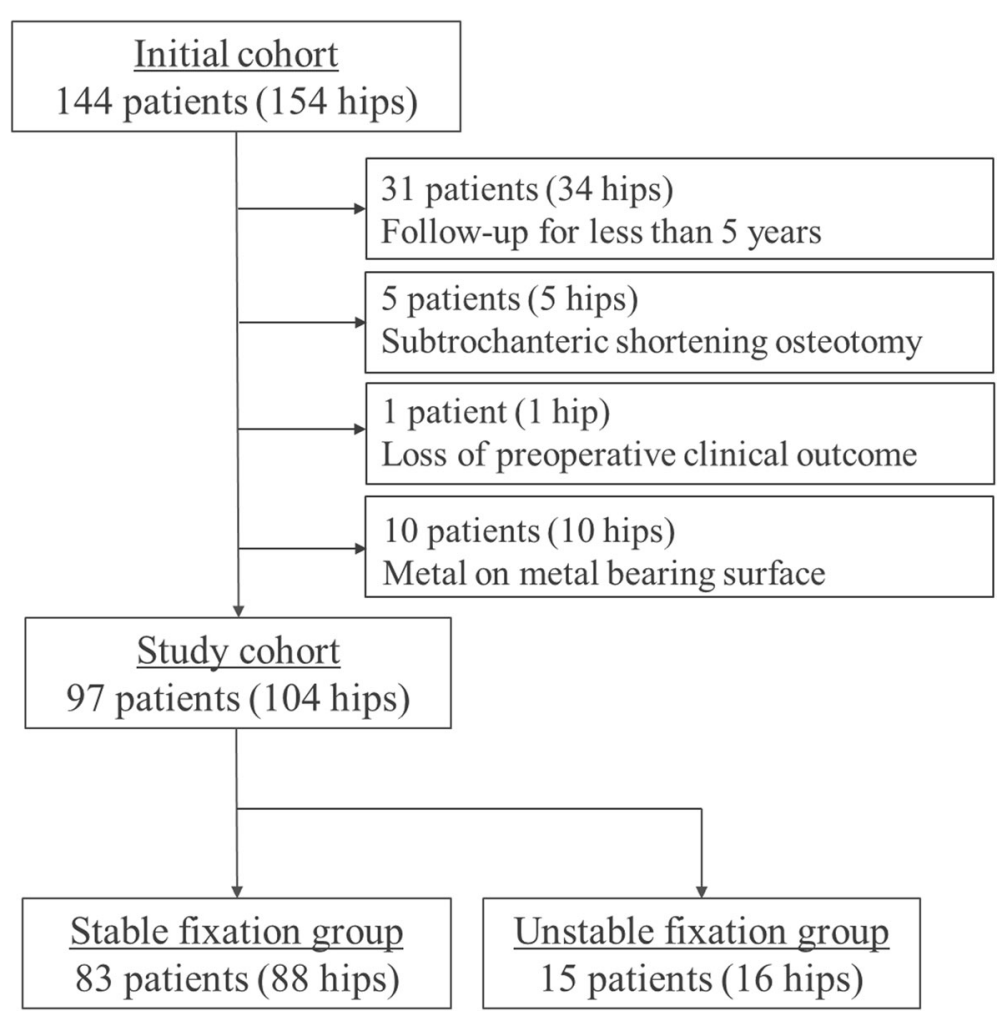

Fig. 1 Flowchart of the study cohort 
had undergone acetabular osteotomy, and 14 patients (13.5\%) had undergone femoral osteotomy. Overall, 36 hips (34.6\%) had severe DDH (Crowe 2 or 3), 36 hips (34.6\%) had lesser or greater femoral anteversion, and 14 hips (13.5\%) had higher posterior pelvic tilt (Table 1).

\section{Surgical data}

Surgery was performed through the Hardinge approach in 83 hips (80\%) and the posterior approach in 21 hips $(20 \%)$ in the lateral decubitus position. The acetabular component was a Pinnacle-A (DePuy) and the STD-CP (cemented cup, JMM, Osaka, Japan) in 96 and eight hips, respectively. The mean outer diameter of the cups was 51 (44-58) $\mathrm{mm}$. All bearing surfaces were cobalt-chromium on highly cross-linked polyethylene. The head diameters were 28,32 , and $36 \mathrm{~mm}$ in 46,57 , and one hips, respectively. Before surgery, pre-operative planning was performed using $2 \mathrm{D}$ templating on the anteroposterior view. The size of the distal stem was determined when distal reaming contacted cortical bone, and the size of the sleeve was determined after proximal and calcar reaming during surgery. If the leg length would be too long, the smaller size of sleeve was used.

\section{Implant survival rate}

The implant survival rate of 97 patients was calculated by the Kaplan-Meier method with revision for any reason as the endpoint.

Table 1 Patients' demographics and clinical outcomes

\begin{tabular}{|c|c|c|c|c|c|c|c|}
\hline & \multicolumn{2}{|c|}{ Total population $(n=104)$} & \multicolumn{2}{|c|}{ Stable group $(n=88)$} & \multicolumn{2}{|c|}{ Unstable group $(n=16)$} & \multirow[t]{2}{*}{$p$ value } \\
\hline & mean \pm SD & (range) & mean \pm SD & (range) & mean \pm SD & (range) & \\
\hline Age (years) & $62 \pm 11$ & $(36-84)$ & $64 \pm 10$ & $(42-84)$ & $55 \pm 9$ & $(36-68)$ & 0.0015 \\
\hline $\operatorname{Sex}(M / F)$ & 20/97 & & $17 / 71$ & & $5 / 11$ & & \\
\hline Height (cm) & $154 \pm 9$ & $(126-174)$ & $154 \pm 9$ & $(126-174)$ & $155 \pm 8$ & $(144-167)$ & 0.77 \\
\hline Weight (kg) & $55 \pm 10$ & $(33-79)$ & $55 \pm 9$ & $(33-79)$ & $60 \pm 12$ & $(38-78)$ & 0.0869 \\
\hline $\mathrm{BMI}$ & $23 \pm 4$ & $(17-34)$ & $23 \pm 3$ & $(17-33)$ & $25 \pm 5$ & $(18-34)$ & 0.0837 \\
\hline Follow-up period (years) & $7.5 \pm 1.2$ & $(5-9.7)$ & $7.6 \pm 1.2$ & $(5-9.7)$ & $7.3 \pm 1.2$ & $(5-8.9)$ & 0.3 \\
\hline \multicolumn{8}{|l|}{ Diagnosis (hips) } \\
\hline Primary osteoarthritis & 7 & & 5 & & 2 & & \\
\hline Osteoarthritis secondary to DDH & 87 & & 73 & & 14 & & \\
\hline Crowe classification $(1,2,3,4)$ & $52,28,7,0$ & & $42,24,7,0$ & & $10,4,0,0$ & & \\
\hline Osteoarthritis secondary to trauma & 2 & & 2 & & 0 & & \\
\hline Rheumatoid arthritis & 1 & & 1 & & 0 & & \\
\hline Osteonecrosis & 2 & & 2 & & 0 & & \\
\hline Rapidly destructive coxarthropathy & 3 & & 3 & & 0 & & \\
\hline Trauma & 2 & & 2 & & 0 & & \\
\hline Acetabular osteotomy (hips) & 21 & & 16 & & 5 & & \\
\hline Femoral osteotomy (hips) & 14 & & 10 & & 4 & & \\
\hline \multicolumn{8}{|l|}{ Preoperative JOA score } \\
\hline Total & & & $50 \pm 12$ & $(22-77)$ & $51 \pm 6$ & $(43-61)$ & 0.31 \\
\hline Pain & & & $16 \pm 8$ & $(0-30)$ & $17 \pm 7$ & $(10-30)$ & 0.65 \\
\hline $\mathrm{ROM}$ & & & $12 \pm 4$ & $(2-20)$ & $10 \pm 5$ & $(3-20)$ & 0.1395 \\
\hline Walk & & & $9 \pm 4$ & $(0-18)$ & $10 \pm 4$ & $(5-15)$ & 0.46 \\
\hline$A D L$ & & & $12 \pm 3$ & $(4-20)$ & $14 \pm 3$ & $(10-20)$ & 0.0495 \\
\hline \multicolumn{8}{|l|}{ JOA score at final follow-up } \\
\hline Total & & & $83 \pm 11$ & $(43-100)$ & $82 \pm 14$ & $(55-100)$ & 0.75 \\
\hline Pain & & & $37 \pm 5$ & $(20-40)$ & $34 \pm 6$ & $(20-40)$ & 0.0946 \\
\hline ROM & & & $17 \pm 3$ & $(4-20)$ & $14 \pm 5$ & $(6-20)$ & 0.0605 \\
\hline Walk & & & $13 \pm 5$ & $(0-20)$ & $16 \pm 4$ & $(5-20)$ & 0.0739 \\
\hline ADL & & & $16 \pm 3$ & $(4-20)$ & $17 \pm 3$ & $(12-20)$ & 0.44 \\
\hline
\end{tabular}

$S D$ standard deviation, $B M I$ body mass index, $D D H$ developmental dysplasia of the hip, $R O M$ range of motion, $A D L$ activities of daily living 


\section{Sleeve fixation}

Sleeve fixation was classified as stable fixation or unstable fixation following Engh's classification [18, 19]. Stable fixation was defined as no or slight radiolucent lines around the sleeve. Spot welds around the distal sleeve were considered evidence of bone ingrowth. Unstable fixation was defined as an extensive radiolucent line around the sleeve $(>50 \%)$ with progressive subsidence or migration (Fig. 2).

\section{Groups}

Patients were separated into two groups including 88 with stable fixation and 16 with unstable fixation of the stem at final follow-up. We compared clinical outcomes, stem alignment, and the canal filling ratio (Fig. 1).

\section{Clinical evaluation}

The Japanese Orthopaedic Association (JOA) hip score was evaluated pre-operatively, post-operatively at 6 months, and then annually. The JOA score ranges from 0 to 100 points and is used to evaluate clinical outcomes of the hip joint. It is composed of four parameters: pain ( 0 to 40 points), range of motion (0 to 20 points), walking ability ( 0 to 20 points), and daily living activities ( 0 to 20 points). The JOA hip score of revision cases was determined at final follow-up before revision.
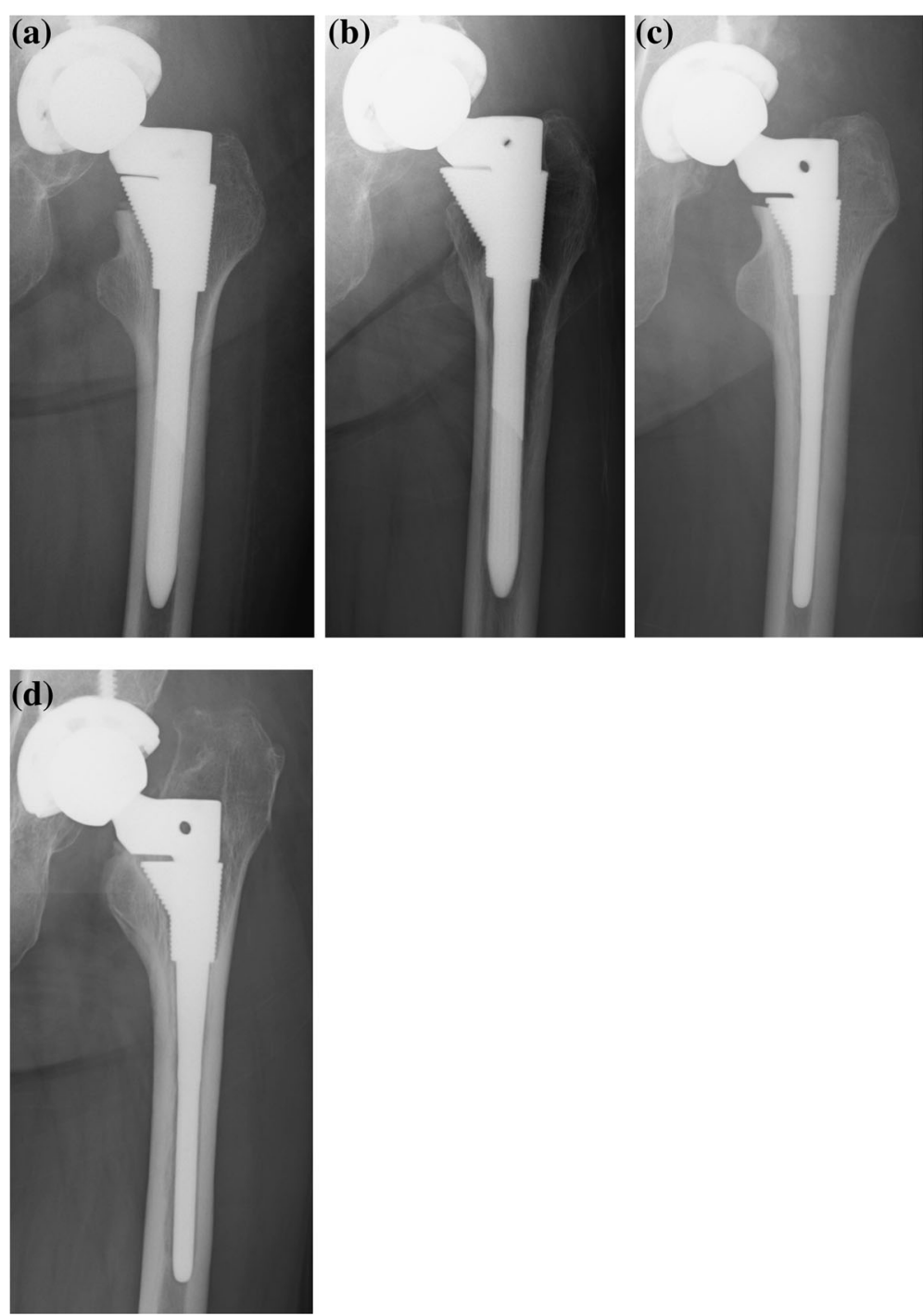

Fig. 2 Stem with stable fixation and unstable fixation 1 week $(\mathbf{a}, \mathbf{c})$ and 5 years $(\mathbf{b}, \mathbf{d})$ after surgery. Spot welds around the distal sleeve were confirmed in the stable fixation (b). Extensive radiolucent line around the sleeve was confirmed with progressive subsidence and varus stem alignment change in the unstable fixation (d) 


\section{Radiographic evaluation}

All radiological data were measured three times by a single author (KK), and the average was taken. Interobserver agreement of canal filling ratio was measured by $\mathrm{KK}$, and TM. Regarding the canal flare index (CFI) and the canal filling ratio measurement, cases of postosteotomy of the femur (12 stable group and 2 unstable group) were excluded because their intramedullary canals were unclear. The CFI was defined as the width of the intramedullary canal at $20 \mathrm{~mm}$ above the lesser trochanter divided by the width of the isthmus [20]. Canal shape was separated into champagne flute (CFI > 4.7), normal (CFI 3.0-4.7), and stovepipe (CFI <3.0). Coronal stem alignment was evaluated at post-operative 1 week and at final follow-up; $>2^{\circ}$ was defined as varus, and valgus was defined as against the bone axis. Coronal stem alignment change was calculated as stem alignment at final follow-up subtracted by stem alignment at postoperative one week. Stress shielding in the stable fixation group was evaluated using Engh's classification [18]. The presence of a radiolucent line around the sleeve was assessed on the anteroposterior view of the X-ray at post-operative 1 year and at final follow-up. The canal filling ratio was defined as the width of the stem divided by the width of the intramedullary canal [21], measured at the level of the bone resection line, at half the height of the sleeve, at the distal end of the sleeve, at half the height of the distal stem on the anteroposterior view and the distal end of the sleeve, and at half the height of the distal stem on the lateral view taken within 1 week after surgery (Fig. 3). Periprosthetic osteolysis was defined as a rounded or scalloped lesion around the implant at least $1 \mathrm{~mm}$ wide, and it increased in size [22].

\section{Statistical analysis}

Intergroup differences in dichotomous continuous or binary variables were tested for significance using the Wilcoxon test or Fisher's exact test. $P<0.05$ was considered significant. Interobserver agreement was calculated using intraclass correlation coefficients (ICCs) and interpreted as follows [23]: $<0.4$ poor; $0.4-0.59$ fair; 0.6-0.74 good; and 0.75-1.00 excellent.

\section{Results}

The 5-year and 9-year implant survival rates were 99\% and $93 \%$, respectively, using the endpoint of revision for any reason. The stem revision rate was $5.8 \%$ (6 hips), and the mean duration to revision was 5.8 (4.4-7.4) years. The reasons for revision were recurrent dislocation (1 hip) and aseptic loosening of the stem (5 hips). Stable sleeve fixation was seen in 88 hips (84.6\%), with unstable fixation in 16 hips (15.4\%). Intraoperative fracture occurred in eight hips (7.7\%). Recurrent dislocation occurred in one hip (1\%), and post-operative periprosthetic fracture occurred in one hip (1\%). There were no infections and no evidence of osteolysis.

In the stable fixation group, age was significantly younger $(P=0.0015)$. Although the pre-operative JOA
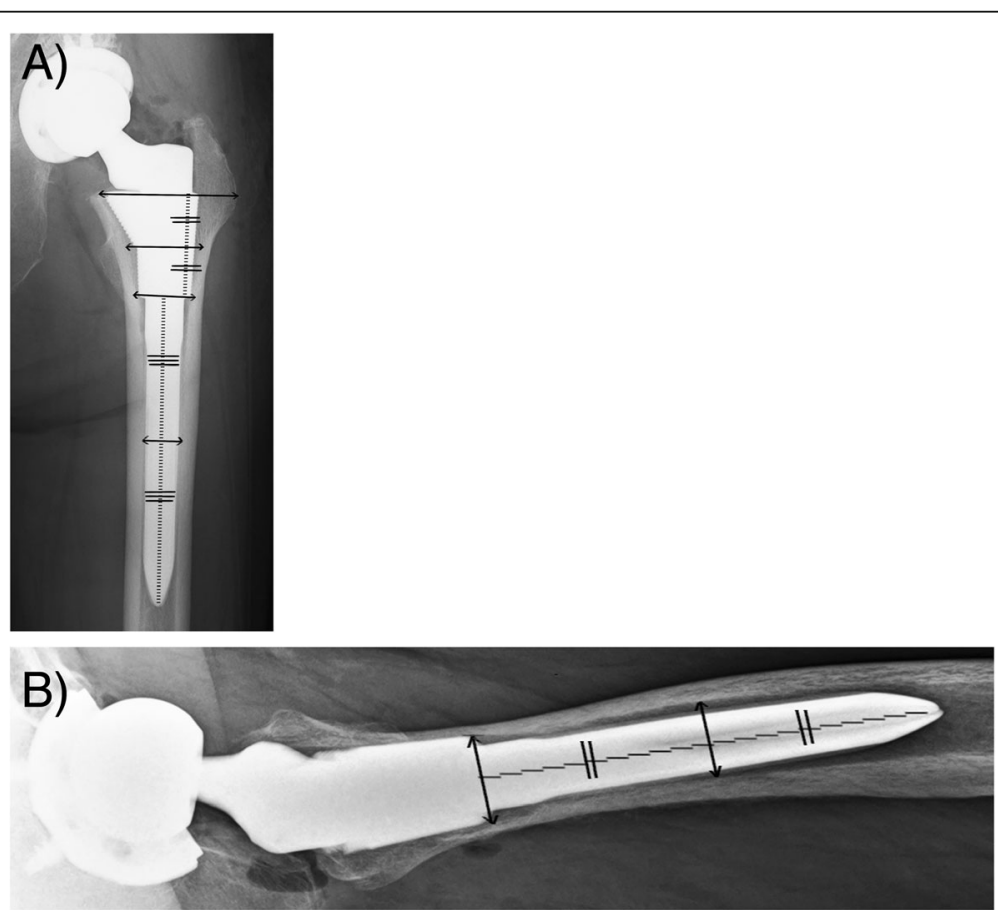

Fig. 3 Measurement levels of the canal filling ratio on the anteroposterior (a) and lateral views (b). The canal filling ratio was defined as the width of the stem divided by the width of the intramedullary canal, measured at the each level 
scores for activities of daily living $(P=0.0495)$ were significantly higher, there was no significant difference in JOA scores at final follow-up (Table 1). The mean CFI was significantly higher in the unstable group $(P=$ 0.0262). The intra- and interobserver agreements were good to excellent for canal filling ratio measurements (Table 2). The canal filling ratio at each level on the anteroposterior and lateral view was significantly lower in the unstable group (Table 3).

One hip (1\%) in the stable group and none in the unstable group had varus coronal stem alignment at postoperative one week. At final follow-up, three hips (3.4\%) in the stable group and four hips (25\%) in the unstable group had varus coronal stem alignment (Table 3). Stem alignment changed $\geq 2^{\circ}$ in one hip (1\%) in the stable group and seven hips (43.8\%) in the unstable group (Fig. 4, Table 3). Grades 3 and 4 severe stress shielding was seen in five hips (5.7\%) and four hips (4.6\%), respectively, in the stable group at final follow-up.

\section{Discussion}

\section{Femoral component survival rate and revision}

To the best of our knowledge, this is the first report of unstable fixation and aseptic loosening using the modified S-ROM prosthesis in primary THA. So far, there have been some reports of the mid- to longterm results of the S-ROM and S-ROM-A prostheses in primary THA. Le et al. and Biant et al. reported that no femoral components were revised with mean follow-up durations of 17 years and 10 years, respectively, using the S-ROM prosthesis [11, 12]. Sato et al. reported a 10-year femoral component survival rate of $84 \%$ for the S-ROM-A prosthesis, and the reason for all revisions was adverse reaction to the metal debris (ARMD) [16]. They used metal on metal, metal on polyethylene, and ceramic on polyethylene bearing surfaces, and the revision rates were $10.3 \%, 2.5 \%$, and $0 \%$ respectively. In the present study, the 9-year femoral component survival rate was $93 \%$. The reasons for femoral component revision were recurrent dislocation (1 hip) and aseptic loosening (5 hips). In the former, the femoral component was revised using the
S-ROM-A prosthesis to change anteversion, and no dislocation occurred after revision. In the latter, the femoral components were revised using cemented stems.

\section{Stem fixation}

Cameron reported that they used the S-ROM prosthesis in 202 primary THA cases, and there was no evidence of loosening with a follow-up period of 2 to 8 years [9]. Le et al. reported that all 31 hips achieved bone ingrowth with a minimal follow-up of 15 years using the S-ROM prosthesis [11]. Kido et al., Tamegai et al., and Hozumi et al. reported that bone ingrowth of the sleeve was achieved in $97.1 \%$ with a mean follow-up of 2.3 years [13], 99.5\% with a mean follow-up of 3.3 years [14], and $97 \%$ with a mean follow-up of 4.6 years, respectively [15]. Sato et al. reported excellent mid-term fixation of the S-ROM-A prosthesis. All stems showed bone ingrowth in 331 hips [16]. Compared to these previous reports, the present results for stem fixation were worse. Sixteen hips (15.4\%) showed extensive radiolucent lines around the sleeve $(>50 \%)$ without spot welds at final follow-up. The S-ROM-A prosthesis was designed to be modular and to achieve fit and fill at both the metaphysis and the diaphysis [9]. The proximal parts including the sleeve and stem needed optimal fit and fill to achieve primary fixation of the stem against vertical force. The distal diameter of the stem was also important because it affected proximal stem diameter and generated torsional stability [24]. In the present study, the CFI was significantly higher and the canal filling ratio was significantly lower in the unstable group, and all stems showed extensive radiolucent lines around the sleeve from postoperative 1 year. These findings showed that we failed to achieve primary fixation of the femoral component due to proximal/distal mismatch of the intramedullary canal of the proximal femur using small sleeves at the metaphysis and using an undersized stem following insufficient reaming at the diaphysis. We should have reamed the distal canal to achieve sufficient filling and used sleeves with as large a diameter as possible and pushed them in tightly.

Table 2 Intra- and inter-observer agreements for the canal filling ratio

\begin{tabular}{|c|c|c|c|c|}
\hline & \multicolumn{2}{|c|}{ Intra-observer } & \multicolumn{2}{|c|}{ Inter-observer } \\
\hline & ICC & $95 \% \mathrm{Cl}$ & ICC & $95 \% \mathrm{Cl}$ \\
\hline Resection line & 0.98 & $0.96-0.99$ & 0.82 & $0.70-0.90$ \\
\hline Half the height of the sleeve & 0.98 & $0.96-0.99$ & 0.77 & $0.63-0.88$ \\
\hline Distal end of the sleeve & 0.86 & $0.75-0.93$ & 0.81 & $0.68-0.90$ \\
\hline Half the height of the stem & 0.97 & $0.95-0.99$ & 0.78 & $0.61-0.88$ \\
\hline Distal end of the sleeve on the lateral view & 0.97 & $0.95-0.99$ & 0.71 & $0.53-0.84$ \\
\hline Half the height of the stem on the lateral view & 0.94 & $0.90-0.97$ & 0.81 & $0.68-0.90$ \\
\hline
\end{tabular}

ICC intra-class correlation coefficient, $\mathrm{Cl}$ confidence interval 
Table 3 Radiographic evaluation

\begin{tabular}{|c|c|c|c|c|c|}
\hline & \multicolumn{2}{|c|}{ Stable group $(n=76)$} & \multicolumn{2}{|c|}{ Unstable group $(n=14)$} & \multirow[t]{2}{*}{$P$ value } \\
\hline & mean $\pm S D$ & (range) & mean $\pm S D$ & (range) & \\
\hline Canal flare index & $3.6 \pm 0.7$ & $(2.2-5.5)$ & $4.3 \pm 1.0$ & $(2.7-6.1)$ & 0.0262 \\
\hline \multicolumn{6}{|l|}{ Canal filling ratio (\%) } \\
\hline Resection line & $65.7 \pm 7.7$ & $(51.1-86.7)$ & $60.6 \pm 5.7$ & $(51.1-71.8)$ & 0.0228 \\
\hline Half the height of the sleeve & $69.3 \pm 9.3$ & $(44.8-90.0)$ & $61.3 \pm 9.3$ & $(50.9-87.1)$ & 0.002 \\
\hline Distal end of the sleeve & $82.5 \pm 8.1$ & $(61.8-95.5)$ & $71.0 \pm 4.8$ & $(66.7-85.6)$ & $<0.0001$ \\
\hline Half the height of the stem & $86.9 \pm 5.3$ & $(73.8-95.9)$ & $80.1 \pm 6.1$ & $(70.4-89.8)$ & 0.0005 \\
\hline Distal end of the sleeve on the lateral view & $80.2 \pm 8.5$ & $(52.7-95.8)$ & $68.8 \pm 8.8$ & $(47.7-84.8)$ & $<0.0001$ \\
\hline \multirow[t]{2}{*}{ Half the height of the stem on the lateral view } & $69.4 \pm 6.4$ & $(54.5-85.9)$ & $63.5 \pm 9.5$ & $(39.3-77.6)$ & 0.0197 \\
\hline & \multicolumn{2}{|l|}{ Hips } & \multicolumn{2}{|l|}{ Hips } & \\
\hline \multirow[t]{3}{*}{ Champagne flute/normal/stovepipe } & \multicolumn{2}{|l|}{$6 / 59 / 11$} & \multicolumn{2}{|l|}{$7 / 5 / 2$} & \\
\hline & \multicolumn{2}{|c|}{ Stable group $(n=88)$} & \multicolumn{2}{|c|}{ Unstable group $(n=16)$} & $P$ value \\
\hline & Hips & $(\%)$ & Hips & $(\%)$ & \\
\hline \multicolumn{6}{|l|}{ Preoperative stem alignment } \\
\hline Neutral/Varus/Valgus & $87 / 1 / 0$ & & $16 / 0 / 0$ & & \\
\hline \multicolumn{6}{|l|}{ Stem alignment at final follow up } \\
\hline Neutral/varus/valgus & $85 / 3 / 0$ & & $12 / 4 / 0$ & & \\
\hline \multicolumn{6}{|l|}{ Stem alignment change } \\
\hline$<2^{\circ}$ & 87 & 98.9 & 9 & 56.2 & \\
\hline$\geq 2^{\circ}$ varus & 1 & 1.1 & 7 & 43.8 & $<0.0001$ \\
\hline \multicolumn{6}{|l|}{ Radiolucent line around the sleeve (> 50\%) } \\
\hline Postoperative 1 year & 1 & 0.9 & 18 & 100 & $<0.0001$ \\
\hline Final follow-up & 0 & 0 & 18 & 100 & $<0.0001$ \\
\hline Stress shielding (grade $3 /$ grade 4) & $5 / 4$ & $4.5 / 3.6$ & & & \\
\hline
\end{tabular}

$S D$ standard deviation

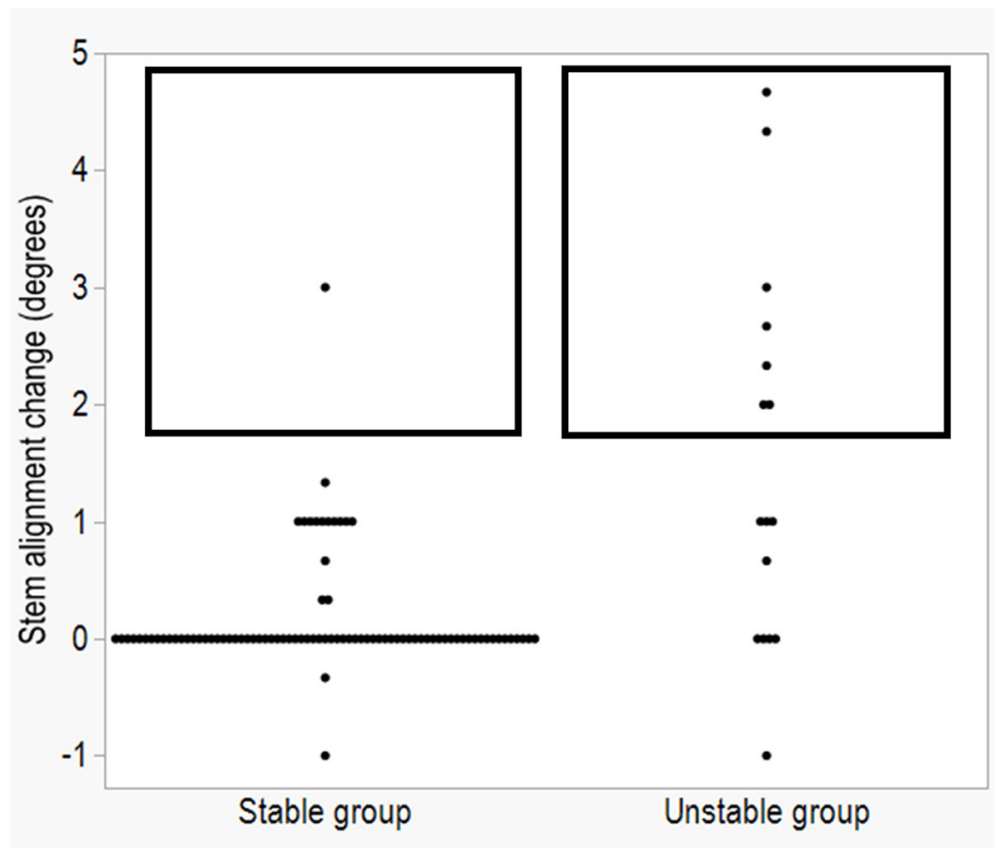

Fig. 4 Stem alignment change in the stable and unstable groups. Rectangle, coronal stem alignment changed $\geq 2^{\circ}$ varus 


\section{Pain and stem alignment change}

Aghayev et al. reported that painful hip increased from 15 to $80 \% 2$ years before revision [25]. In the present study, the post-operative JOA score of pain was not significantly lower in the unstable group, but all revision cases for aseptic loosening had pain during walking. Two of six revision hips (33\%) had continuous pain after surgery, and three hips (50\%) had pain for more than two years before revision.

Regarding the relationship between pain and stem alignment change, three of seven hips (63\%) whose stem alignment gradually changed $\geq 2^{\circ}$ varus in the unstable group had pain, but the others $(37 \%)$ had no pain or only discomfort. Of the eight hips, six were in female patients, and the others (same patient) had protrusion of the acetabulum and a stovepipe femur.

There was a risk of periprosthetic fracture or perforation due to varus stem alignment change at the lateral cortex of the femur. These findings showed that pain was of course important, and sometimes the presence of a radiographic sign was the only useful monitor; it was necessary to revise the stem of female cases and poor bone quality cases with unstable fixation of the sleeve to prevent periprosthetic fracture.

\section{Limitations}

The present study has several limitations. First, this retrospective study did not allow a patient-based assessment of pain and function. Second, in cases of post-osteotomy of the femur, the canal flare index and canal filling ratio (12 stable group and 2 unstable group) were not measured because their intramedullary canals were unclear.

\section{Conclusion}

The S-ROM-A prosthesis was useful to treat anatomically difficult patients as long as surgeons kept its concept in mind. Both the distal stem and the proximal sleeve need to be as large as possible to achieve stable fixation and good long-term results with this prosthesis.

\section{Abbreviations}

THA: TOTAL hip arthroplasty; DDH: Developmental dysplasia of the hip; JOA: The Japanese Orthopaedic Association; CFI: Canal flare index; ICCs: Intraclass correlation coefficients

\section{Acknowledgements}

The author (K Kobayashi) would like to thank Dr. A Hozumi, Dr. H Goto, Dr. J Maeda, and all colleagues for providing the opportunity to embark on this study.

\section{Authors' contributions}

We hereby confirm that all six authors have participated in the study as follows: KK study design, data collection, manuscript editing, statistical analysis, manuscript writing, figure and tables. KK study design, data collection, manuscript editing. Ml data collection, manuscript editing. TM data collection, manuscript editing. KC data collection, manuscript editing.
MO study design, data collection, manuscript editing. All authors read and approved the final manuscript.

\section{Funding}

This research did not receive any specific grant from funding agencies in the public, commercial, or not-for-profit sectors.

\section{Availability of data and materials}

The datasets during and/or analyzed during the current study are available from the corresponding author on reasonable request.

\section{Ethics approval and consent to participate}

The procedures used in this study adhere to the tenets of the Declaration of Helsinki. The Institutional Review Board of Nagasaki University approved this retrospective study (IRB reference number: 19121619), and informed consent was obtained using the opt-out form on the web-site (http://www.mh.naga saki-u.ac.jp/research/rinsho/patients/open_surg-ort.html). Consent to participate was obtained using the opt-out form on the web-site (http://www.mh.naga saki-u.ac.jp/research/rinsho/patients/open_surg-ort.html).

\section{Consent for publication}

Consent to publication was obtained using the opt-out form on the web-site (http://www.mh.nagasaki-u.ac.jp/research/rinsho/patients/open_surg-ort.html).

\section{Competing interests}

The authors declare that they have no conflict of interest.

Received: 29 June 2020 Accepted: 19 November 2020

Published online: 30 November 2020

References

1. Vidalain JP. Twenty-year results of the cementless Corail stem. Int Orthop (SICOT). 2011;35:189-94.

2. $\quad$ Ling R, Charity J, Lee AJ, Whitehouse SL, Timperley AJ, Gie GA. The longterm results of the original Exeter polished cemented femoral component. J Arthroplasty. 2009;24:511-7.

3. Jingushi S, Ohfuji S, Sofue M, Itoman M, Matsumoto T, Hamada $Y$, et al. Multiinstitutional epidemiological study regarding osteoarthritis of the hip in Japan. J Orthop Sci. 2010;15:626-31.

4. Nakamura S, Ninomiya S, Nakamura T. Primary osteoarthritis of the hip joint in Japan. Clin Orthop Relat Res. 1989;241:190-6.

5. Noble PC, Kamaric E, Sugano N, et al. Three-dimensional shape of the dysplastic femur: implications for THR. Clin Orthop Relat Res. 2003; 417:27-40.

6. Urban RM, Gilbert JL, Jacobs JJ. Corrosion of modular titanium alloy stems in cementless hip replacement. J ASTM Int. 2005;2:1-10.

7. Rodrigues DC, Urban RM, Jacobs JJ, Gilbert JL. In vivo severe corrosion and hydrogen embrittlement of retrieved modular body titanium alloy hipimplants. J Biomed Mater Res Part B Appl Biomater. 2009;88B:206-19.

8. Grupp TM, Weik T, Bloemer W, Knaebel HP. Modular titanium alloy neck adapter failures in hip replacement - failure mode analysis and influence of implant material. BMC Musculoskelet Disord. 2010;11:3.

9. Cameron HU. Modularity in primary total hip arthroplasty. J Arthroplasty. 1996;11:332.

10. Tanzer M, Chan S, Brooks E, Bobyn JD. Primary cementless total hip arthroplasty using a modular femoral component. J Arthroplasty. 2001; 16:64-70.

11. Le D, Smith K, Tanzer D, Tanzer M. Modular femoral sleeve and stem implant provides long-term total hip survivorship. Clin Orthop Relat Res. 2011;469:508-13.

12. Biant LC, Bruce WJ, Assini JB, Walker PM, Walsh WR. The anatomically difficult primary total hip replacement: medium- to long-term results using a cementless modular stem. J Bone Joint Surg Br. 2008;90:430-5.

13. Kido K, Fujioka M, Takahashi K, Ueshima K, Goto T, Kubo T. Short-term results of the S-ROM-A femoral prosthesis. J Arthroplasty. 2009;24:1193-9.

14. Tamegai H, Otani T, Fujii H, Kawaguchi Y, Hayama T, Marumo K. A modified SROM stem in primary total hip arthroplasty for developmental dysplasia of the hip. J Arthroplasty. 2013;28:1741-5.

15. Hozumi A, Kobayashi K, Tsuru N, et al. Total hip arthroplasty using the SROM-A prosthesis for anatomically difficult Asian patients. BioMed Res Int. 2015;7. https://doi.org/10.1155/2015/690539. 
16. Sato A, Okuda N, Tsukada S, Kimura A, Kase M, Matsubara M. Midterm outcomes and frequency of osteolysis of total hip arthroplasty using cementless modular stem for Asian patients. J Arthroplasty. 2019;35(3):811-7.

17. Garbossa D, Pejrona M, Damilano M, Sansone V, Ducati A, Berjano P. Pelvic parameters and global spine balance for spine degenerative disease: the importance of containing for the well being of content. Eur Spine J. 2014; 23(Suppl 6):616-27.

18. Engh CA, Bobyn JD, Glassman AH. Porous-coated hip replacement. The factors governing bone ingrowth, stress shielding, and clinical results. J Bone Joint Surg Br. 1987;69:45-55.

19. Engh CA, Massin P, Suthers KE. Roentgenographic assessment of the biologic fixation of porous-surfaced femoral components. Clin Orthop Relat Res. 1990;257:107-28.

20. Noble PC, Box GG, Kamaric E, Fink MJ, Alexander JW, Tullos HS. The effect of aging on the shape of the proximal femur. Clin Orthop Relat Res. 1995;316:31-44.

21. Ishii S, Homma Y, Baba T, Ozaki Y, Matsumoto M, Kaneko K. Does the canal fill ratio and femoral morphology of Asian females influence early radiographic outcomes of total hip arthroplasty with an uncemented proximally coated, tapered-wedge stem? J Arthroplasty. 2016;31:1524-8.

22. Zicat B, Engh CA, Gokcen E. Patterns of osteolysis around total hip components inserted with and without cement. J Bone Joint Surg Am. 1995;77:432-9

23. Cicchetti D. Guidelines, criteria, and rules of thumb for evaluating normed and standardized assessment instruments in psychology. Psychol Assess. 1994;6:284-90.

24. Kang JS, Moon KH, Kim RS, Park SR, Lee JS, Shin SH. Total hip arthroplasty using S-ROM prosthesis for dysplastic hip. Yonsei Med J. 2011;52:655-60.

25. Aghayev E, Teuscher R, Neukamp M, et al. The course of radiographic loosening, pain and functional outcome around the first revision of a total hip arthroplasty. BMC Musculoskelet Disord. 2013;14:167.

\section{Publisher's Note}

Springer Nature remains neutral with regard to jurisdictional claims in published maps and institutional affiliations.

Ready to submit your research? Choose BMC and benefit from:

- fast, convenient online submission

- thorough peer review by experienced researchers in your field

- rapid publication on acceptance

- support for research data, including large and complex data types

- gold Open Access which fosters wider collaboration and increased citations

- maximum visibility for your research: over $100 \mathrm{M}$ website views per year

At $\mathrm{BMC}$, research is always in progress.

Learn more biomedcentral.com/submissions 